\title{
The EMPMD: A Positive Force in TMS Programming
}

\author{
Zi-Kui Liu
}

As one of the five TMS technical divisions, EMPMD consists of the fol-

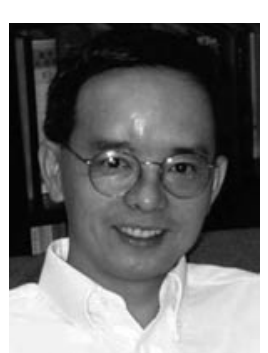
lowing technical committees: Alloy Phases; Biomaterials; Chemistry and Physics of Materials; Electronic Materials; Electronic Packaging and Interconnection Materials; Energy Conversion and Storage Materials; Magnetic Materials; Nanomaterials; Thin Films and Interfaces. The first three committees are also with the Structural Materials Division, and focus their symposia on functional materials.

The Alloy Phases Committee covers metallic phases in relation to thermodynamics, phase equilibria, crystal structure, atomic parameters, and electronic structures. The committee also supports the selection procedure for the HumeRothery Award and sponsors the corresponding Hume-Rothery Symposium at TMS Annual Meetings.

The Biomaterials Committee develops programming at the TMS Annual Meeting and the Materials Science and Technology (MS\&T) meetings. The leading topics relate to biomaterials processing, characterization, in vitro testing, and modeling. These symposia include sessions on nanoparticles for medical diagnosis and treatment, functional nanobiomaterials, novel medical alloys, biologically derived materials, biomimetic materials, surface modification of biomaterials, novel materials for tissue engineering, and novel materials for drug delivery.

The Chemistry and Physics of Materials Committee hosts historically wellattended recurring symposia, such as Computational Thermodynamics and
Kinetics, Frontiers in Solidification Science, and Emerging Applications of Neutron Scattering in Materials Science and Engineering. Future focus is anticipated on the fundamental chemical and physical processes for production, storage, and transfer of renewable energy.

The Electronic Materials Committee organizes technical meetings and conferences to facilitate dissemination of scientific and engineering knowledge in the broad area of electronic materials and the associated materials sciences, primarily through the annual Electronic Materials Conference. In addition, the committee sponsors and manages the publication of the Journal of Electronic Materials, and grants student awards for oral and written work.

The Electronic Packaging and Interconnection Materials Committee provides within the framework of TMS a national organization for scientists and engineers with a common interest in the structure-properties-processing relationship of electronic packaging and interconnect materials, structures, and technologies. This committee organizes symposia, such as the highly popular lead-free solder symposia, publishes a special issue in Journal of Electronic Materials at least once a year, conducts specialized courses and/or workshops, and nominates members for divisional and society level awards.

The newly established Energy Conversion and Storage Materials Committee aims to foster the development of materials to enable clean power systems to reduce greenhouse gas emissions and meet the global demand for energy. Its scope includes advanced materials understanding and development, processing and application of the materials for advanced energy conversion and storage systems.
The Magnetic Materials Committee has been recently renamed from the Superconducting and Magnetic Materials Committee to focus on the existing expertise at TMS. The formal reorganization of the committee is expected to take place in connection with the symposium Magnetic Materials: Structure, Thermodynamics, and Properties at MS\&T 2009 in honor of Prof. David Laughlin for the EMPMD Distinguished Scientist Award.

The Nanomaterials Committee focuses on the relationship between structure, property, and performance on a microscopic level in functional materials. Its symposia address the application, fabrication, and fundamental materials science of nanomaterials, a class of materials whose morphology, structure, or performance is dominated by phenomena attributed to the "nano" length scale $(<100 \mathrm{~nm})$.

The Thin Films and Interface Committee aims to advance thin film technology by closely tracking scientific and engineering achievements and fostering the exchange of ideas. The technological wonders of current society owe greatly to the introduction of novel materials, especially in the form of thin films, and improved understanding of the mechanisms governing their properties. It is the mission of this committee to take the leading role in this constantly evolving field.

The EMPMD provides a wide breadth of symposium topics with strong interactions among its technical committees. I encourage you to share your expertise through committee involvement.

Zi-Kui Liu is a professor in the Department of Materials Science and Engineering at Pennsylvania State University and is the TMS Director of the Electronic, Magnetic \& Photonic Materials Division. 